\title{
Topical nonsteroidal anti-inflammatory drugs for the treatment of pain due to soft tissue injury: diclofenac epolamine topical patch
}

REVIEW

This article was published in the following Dove Press journal:

Journal of Pain Research

9 November 2010

Number of times this article has been viewed

\author{
David R Lionberger' \\ Michael J Brennan² \\ 'Southwest Orthopedic Group, \\ Houston, TX, USA; 2Department \\ of Medicine, Bridgeport Hospital, \\ Bridgeport, CT, USA
}

Correspondence: David R Lionberger SW Orthopedic Group, 6560 Fannin St, Ste 1020, Houston, TX 77030, USA

$\mathrm{Tel}+\mathrm{I} 7133334100$

Fax +17133334101

Email dlionberger@mysurgeon.com
Abstract: The objective of this article is to review published clinical data on diclofenac epolamine topical patch $1.3 \%$ (DETP) in the treatment of acute soft tissue injuries, such as strains, sprains, and contusions. Review of published literature on topical nonsteroidal antiinflammatory drugs (NSAIDs), diclofenac, and DETP in patients with acute soft tissue injuries was included. Relevant literature was identified on MEDLINE using the search terms topical NSAIDs, diclofenac, diclofenac epolamine, acute pain, sports injury, soft tissue injury, strain, sprain, and contusion, and from citations in retrieved articles covering the years 1978-2008. Review of published, randomized clinical trials and meta-analyses shows that topical NSAIDs are significantly more effective than placebo in relieving acute pain; the pooled average relative benefit was 1.7 (95\% confidence interval, 1.5-1.9). In a limited number of comparisons, topical and oral NSAIDs provided comparable pain relief, but the use of topical agents produced lower plasma drug concentrations and fewer systemic adverse events (AEs). The physical-chemical properties of diclofenac epolamine make it well suited for topical use. In patients with acute soft tissue injuries treated with DETP, clinical data report an analgesic benefit within hours of the first application, and significant pain relief relative to placebo within 3 days. Moreover, DETP displayed tolerability comparable with placebo; the most common AEs were pruritus and other application site reactions. Review of published literature suggests that DETP is generally safe and well tolerated, clinically efficacious, and a rational treatment option for patients experiencing acute pain associated with strains, sprains, and contusions, and other localized painful conditions.

Keywords: diclofenac epolamine, topical analgesics, soft tissue injury, strains, sprains, contusions

\section{Introduction}

Muscle and musculoskeletal injuries, including sprains, strains, and contusions, comprise the majority of sports-related injuries. ${ }^{1-3}$ Sprains resulting from joint injuries are graded from I to III (mild to severe or by number and extent of ligaments involved) and most frequently affect the ankle. ${ }^{2}$ Sprains involve some degree of tearing and stretching of a supporting ligament, ${ }^{2}$ whereas strains refer to partial or complete tearing of the muscletendon unit. ${ }^{1}$ Muscle contusions result from direct blunt trauma to muscle fibers, causing damage to the structure and function of the muscle. ${ }^{3}$ Each of these injuries produces local tissue inflammation, which causes pain, swelling, tenderness, limited mobility, and if sufficiently severe, disability. ${ }^{2,3}$ Moreover, initial treatment is similar depending on the severity of the injury. In general, initial treatment consists of rest, ice, compression, and elevation (RICE) and use of nonsteroidal anti-inflammatory drugs (NSAIDs) to limit 
the extent of inflammation and pain and promote their early resolution. ${ }^{3-5}$ Depending on the injury, exercise and rehabilitation are then used to restore strength and range of motion, and to promote proper healing.

\section{Soft tissue injury}

Acute ankle injuries account for an estimated 20\% of all sports-related injuries and, of these, $85 \%$ are sprains typically involving inversion injuries to the lateral stabilizing ligaments (ie, anterior talofibular, calcaneofibular, and posterior talofibular). ${ }^{2,6-8}$ About 5\% result from eversion injuries of the deltoid or medial ligaments. ${ }^{8}$ Conservative treatment with early weight bearing, bracing, and functional rehabilitation is generally the accepted approach for managing ankle sprains. ${ }^{2} \mathrm{~A}$ recent, systematic review of 24 high-quality clinical studies assessing the clinical course of ankle sprains revealed that there is a rapid decrease in patient reports of pain over the first 2 weeks following the injury. ${ }^{9}$ The initial pain and swelling following an ankle sprain may limit the patient's ability to perform the rehabilitation necessary for proper healing. ${ }^{10}$ Moreover, fluid accumulation around the site of injury may exacerbate tissue damage, delay healing, and eventually lead to some degree of chronic disability. ${ }^{11}$ Accordingly, the initial emphasis of treatment after injury is to rapidly reduce pain and inflammation with RICE and use of NSAIDs during post-injury and the initial rehabilitation program. ${ }^{4}$ NSAIDs have been shown to effectively reduce pain and inflammation, improve function, and allow more rapid return to normal activity after ankle sprains. ${ }^{6}$ Although most ankle sprains do not lead to significant disability, residual pain is prevalent in 5\%-33\% of patients for up to 1 year after injury; in some patients, ankle symptoms, such as lateral instability, also persist. ${ }^{9}$

Acute muscle strains are partial tears of the tendinous insertion into the muscle at the distal myotendinous junction, which are caused by excessive stretching while the muscle is being activated or during excessive use. ${ }^{5,12}$ In general, muscles that cross two or more joints and those with a higher percentage of type II muscle fibers are particularly susceptible to strains (eg, hamstring, quadriceps, gastrocnemius). ${ }^{1,5}$ The degree of damage depends on how much force was placed on the muscle in relation to the muscle resistance and, in turn, is associated with the magnitude of pain and inflammation. ${ }^{5}$ Hemorrhage and hematoma formation are commonly seen in acute strains. Treatment is based on the severity of the injury and includes RICE and NSAIDs in the acute setting. ${ }^{3,5}$ During the healing phase, stretching and strengthening exercises are often added. ${ }^{3}$

Contusions resulting from direct blunt trauma to muscle fibers may cause capillary rupture, bleeding, hematoma formation, and eventually an intense inflammatory response. ${ }^{5}$ Mild contusions cause localized tenderness with little, if any, loss in range of motion, whereas severe contusions present with marked tenderness and swelling and less than 50\% range of motion. ${ }^{5}$ RICE is used initially to limit the range of motion of the affected extremity and minimize the risk of hemorrhage, and NSAIDs are introduced in the acute setting to provide early resolution of pain and inflammation. ${ }^{3}$ This is followed by restoration of active and active-assisted range-of-motion exercises and, subsequently, by functional rehabilitation and resistance exercises. ${ }^{5}$

\section{Use of oral NSAIDs in the management of soft tissue injuries}

NSAIDs provide the cornerstone for the treatment of acute pain and inflammation. ${ }^{11,13}$ Clinical studies in patients with soft tissue injuries demonstrate that NSAIDs provide symptomatic relief of pain and allow faster recovery and return to normal activities when compared with placebo. ${ }^{11,13}$ On the basis of these benefits, NSAIDs have a role in the short-term management of soft tissue injuries. They should be used judiciously for as short a period as possible and at the lowest possible effective dose, based on the type of injury and level of dysfunction and pain. ${ }^{13}$ In general, a short course of NSAID therapy lasting 3-7 days after ligament sprains and muscle injury is likely to be beneficial, but the effects of their long-term use remain controversial. ${ }^{13}$ Use of NSAIDs in acute tendonitis and tenosynovitis is also reasonable in the days immediately after injury, when some amount of inflammation is expected. ${ }^{13}$

The analgesic and anti-inflammatory effects of NSAIDs are mediated via their inhibition of prostaglandin biosynthesis. Traditional NSAIDs, such as diclofenac, inhibit both cyclooxygenase-1 (COX-1) and COX-2 isoenzymes, which are rate-limiting enzymes in the prostaglandin biosynthetic pathway. ${ }^{14,15}$ At pharmacologically effective doses, systemic NSAID therapy may produce a variety of adverse events (AEs) related to the inhibition of prostaglandin synthesis involved in maintaining normal physiological processes. For example, inhibition of the COX-1 isoenzyme in gastrointestinal mucosa is known to be responsible for the increased risk of gastrointestinal AEs associated with traditional NSAID use. This led to the design and development of the COX-2-selective inhibitors, such as celecoxib and etoricoxib, which display reduced risk of gastrointestinal AEs compared with traditional NSAIDs. ${ }^{16}$

Gastrointestinal toxicity, including serious gastrointestinal perforations, ulcers, or bleeding, can often limit the 
use of traditional NSAIDs. ${ }^{17}$ Poor tolerability due to upper gastrointestinal symptoms, often categorized as dyspepsia, is a significant cause of treatment discontinuation. ${ }^{18}$ The prevalence of dyspepsia in patients treated with traditional NSAIDs can be high, ranging from 5\%-50\%. ${ }^{19}$ Due to the role of the COX-2 isoenzyme in renal prostaglandin biosynthesis, both traditional and selective NSAIDs are associated with renovascular AEs; risk may be increased in agents with a longer half-life. ${ }^{20,21}$

The AEs associated with oral NSAID therapy also have a significant economic consequence. A retrospective database analysis found that direct medical costs were increased by nearly $\$ 1$ per day due to gastrointestinal events related to NSAID use in an elderly population. ${ }^{22}$ Other studies have shown that reducing gastrointestinal events by switching from oral NSAIDs to topical agents would reduce medical costs. ${ }^{23}$

\section{Topical NSAIDs General}

Topical NSAIDs are designed to be applied over the site of injury and exert their analgesic and anti-inflammatory effects in the underlying superficial, musculoskeletal soft tissue. Topical NSAIDs work locally and are not dependent on systemic absorption and subsequent redistribution into peripheral tissues. ${ }^{24}$ Accordingly, topical application of NSAIDs differs from transdermal drug delivery, which is designed to provide active drug to the systemic circulation and exert effects at sites distant from the application site. ${ }^{25}$

\section{Benefits}

Topical application of NSAIDs offers a number of potential benefits compared with oral systemic delivery. NSAIDs, when administered topically, are generally well tolerated with AEs mainly limited to mild skin irritation - erythema, dermatitis, and pruritus - that resolves upon discontinuation. ${ }^{26}$ Topical administration results in significantly lower systemic drug exposure, reducing the risks of dose-dependent NSAID-associated AEs. ${ }^{27}$ In the event of an untoward effect, the topical dose can be easily terminated. ${ }^{25}$ Topical application can also avoid extensive first-pass metabolism, as is seen with oral diclofenac formulations. Other advantages of topical drugs include direct access, delivery, localization at site of action, and the option of prolonged use, ${ }^{28-30}$ ease of use may lead to improved patient compliance and adherence to the prescribed regimen. ${ }^{31-33}$ Moreover, topical drugs may be a viable option for patients who cannot use oral medications. ${ }^{25}$

\section{Pharmacokinetics}

Pharmacokinetic studies, which included diclofenac, ketorolac, and ketoprofen in various formulations, including gels, ointments, and patches, found that peak plasma NSAID concentrations following topical application are $0.2 \%-8 \%$ of those seen after oral dosing. ${ }^{15}$ Additionally, the time to achieve peak levels following topical application was approximately 10 -fold longer than the corresponding time following an equivalent oral dose and ranged from 2.2 to 23 hours. ${ }^{15}$ With multiple topical doses, steady state is achieved within 2-5 days, and $\mathrm{C}_{\max }$ is about 2.5 times higher than $\mathrm{C}_{\max }$ following a single topical dose; however, serum concentrations remain $>90 \%$ lower than those achieved after oral NSAIDs. ${ }^{34,35}$ Application of a diclofenac epolamine topical patch (DETP) in 10 healthy male volunteers (twice daily for 7 days) produced peak plasma drug levels nearly 100 times lower than those achieved after a single 50-mg, oral dose of diclofenac with area under curve values that were 10-20 times lower over 48 hours. ${ }^{36,37}$

\section{Efficacy}

The efficacy of topical NSAIDs was assessed in a metaanalysis of 61 randomized controlled trials that involved a total of 7,727 patients with acute pain. ${ }^{27}$ Trials were included if a topical NSAID was compared with placebo, another topical NSAID, or an oral NSAID in recent soft tissue injury, sprain, strain, or trauma. Of 37 placebo-controlled trials, 27 showed that the topical NSAID was significantly superior to placebo, and 9 additional studies showed a trend favoring the topical drug (Figure 1). ${ }^{27}$ Overall, the pooled relative benefit was 1.7 (95\% confidence interval [CI]: 1.5-1.9), and the number needed to treat (NNT) to achieve a successful outcome with topical NSAIDs was $3.9(95 \%$ CI: 3.4-4.4). The 24 studies that compared topical NSAIDs with one another or with an oral NSAID found no difference in efficacy between treatments. ${ }^{27}$ Overall, the incidence of local AEs (2.6\% vs 3.0\%), systemic AEs ( $0.8 \%$ vs $0.7 \%$ ), and AEs leading to withdrawal of treatment ( $0.6 \%$ vs $0.4 \%)$ did not differ significantly between the topical NSAIDs and placebo. ${ }^{27}$ This meta-analysis also included 25 additional trials involving 2,433 patients with chronic pain conditions, including osteoarthritis and other rheumatologic disorders. ${ }^{27}$ In this analysis, topical NSAIDs were more effective than placebo, with a pooled relative benefit of 2.0 (95\% CI: $1.5-2.7)$ and an NNT of 3.1 (95\% CI: 2.7-3.8). ${ }^{27}$

A subsequent meta-analysis evaluated 26 randomized controlled trials involving 2,853 adults with acute pain resulting from strains, sprains, or sports injuries. ${ }^{38}$ Topical 


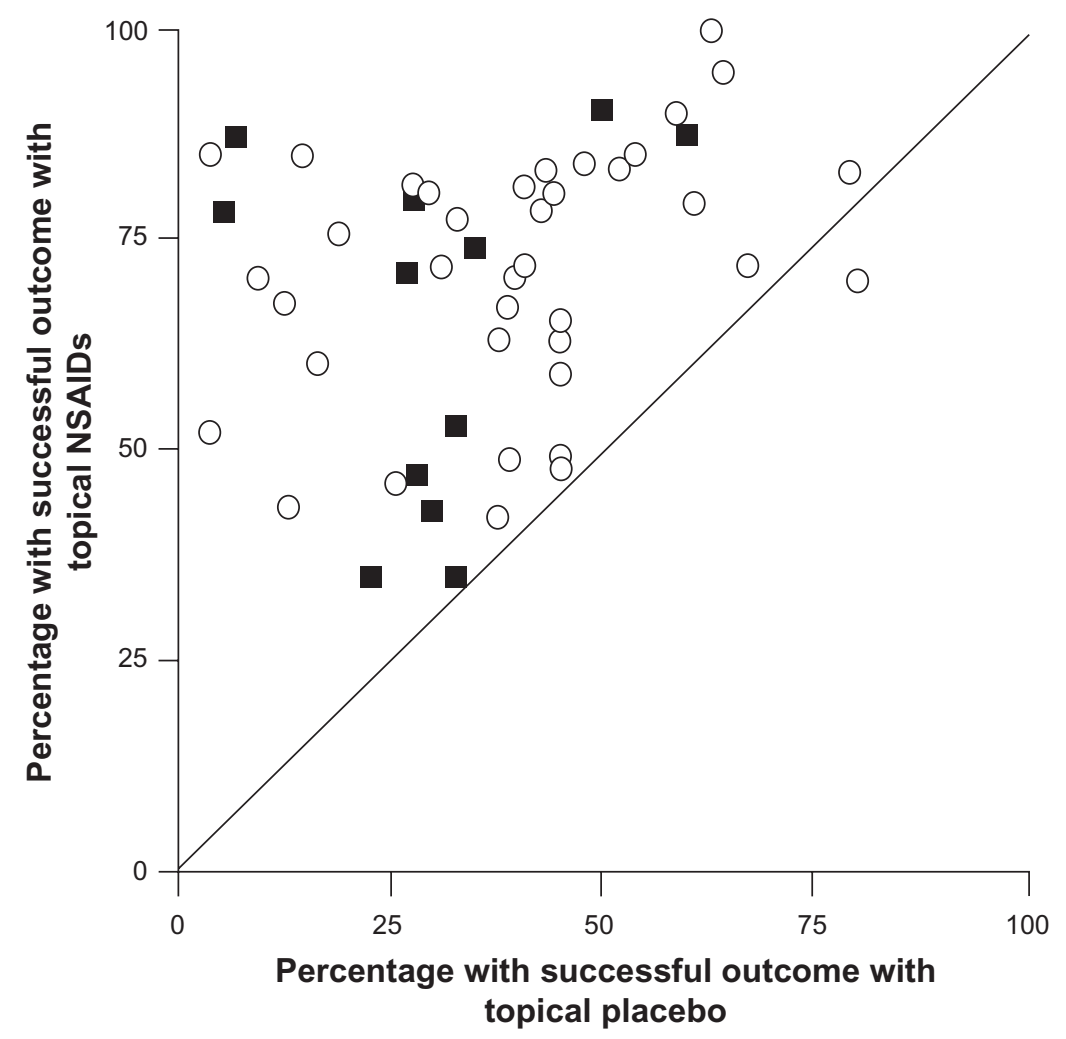

Figure I Success rates with topical nonsteroidal anti-inflammatory drugs (NSAIDs) vs topical placebo in the treatment of acute (open circles) and chronic (filled squares) painful conditions. Outcomes were assessed after 7 days in acute conditions and 14 days in chronic conditions. Copyright @ 1998 , BMJ Publishing Group Ltd. Reproduced with permission from Moore RA, Tramer MR, Carroll D, Wiffen PJ, McQuay HJ. Quantitative systematic review of topically applied non-steroidal anti-inflammatory drugs, BMJ. 1998;316:333-338.

NSAIDs demonstrated significantly better analgesic efficacy than placebo in 19 of the 26 trials and overall produced a relative benefit of $1.6(95 \% \mathrm{CI}: 1.4-1.7)$ and an NNT of $3.8(95 \%$ CI: $3.4-4.4) .{ }^{38}$ When only high-quality and/or high-validity studies were retained in the meta-analysis, the superiority of topical NSAIDs over placebo was still evident with NNT values of 3.7-4.0. Five topical NSAIDs were evaluated in at least 3 clinical trials (ketoprofen, ibuprofen, felbinac, piroxicam, and indomethacin) and all were found to be superior to placebo. ${ }^{38}$ Consistent with the first meta-analysis, incidence of local AEs (4.4\% vs 4.7\%), systemic AEs (2.8\% vs $2.4 \%$ ), and AE-related withdrawals ( $0.8 \%$ vs $0.7 \%)$ was similar between topical NSAIDs and placebo. ${ }^{38}$ Together, these analyses demonstrate that topical NSAIDs are effective and well tolerated in the short-term treatment of acute soft tissue injuries.

\section{Limitations}

Several limitations are inherent to the use of topical NSAIDs. Most notably, since systemic exposure is minimized, these formulations are only effective for the treatment of localized pain at the site of application. Due to the continued contact of the formulation with the skin, localized skin reactions, such as irritant dermatitis and erythema, are observed. ${ }^{27,38}$ However, as noted previously, meta-analyses have shown that these local AEs occur only in a small minority of patients treated for acute soft tissue injuries with topical NSAIDs. ${ }^{27,38}$

\section{Diclofenac}

Diclofenac is a traditional NSAID that possesses antiinflammatory, analgesic, and antipyretic properties through inhibition of COX isoenzymes and blockade of prostaglandin synthesis. ${ }^{39}$ It is among the most widely prescribed NSAIDs worldwide, ${ }^{21}$ and unlike other traditional NSAIDs, such as ibuprofen and naproxen, does not interfere with the antiplatelet effects of low-dose aspirin. ${ }^{21,40,41}$ Diclofenac also has the potential to affect polymorphonuclear leukocyte function in vitro, which may contribute to its anti-inflammatory effects by reducing the ability of these cells to infiltrate into an inflammatory site and produce damaging oxygen radicals and proteases. ${ }^{39}$ Noncomparative clinical studies showed that oral diclofenac sodium has a rapid onset of action in treating soft tissue injuries, including acute strains, sprains, and contusions, with doses of 75-150 mg/d producing clinical improvement in as little as 2-3 days. ${ }^{42}$ Comparative clinical 
trials demonstrated that diclofenac sodium administered as a conventional enteric-coated tablet formulation was at least as effective and well tolerated as other NSAIDs in patients with acute soft tissue injuries. ${ }^{43-45}$ In a randomized controlled trial of 139 patients with acute sports injuries, diclofenac sodium $150 \mathrm{mg} / \mathrm{d}$ allowed an earlier return to sport-playing fitness than aspirin $3.6 \mathrm{~g} / \mathrm{d},{ }^{44}$ and in another randomized controlled trial of 151 patients with acute strains, diclofenac sodium $100 \mathrm{mg} / \mathrm{d}$ was as effective as indomethacin $100 \mathrm{mg} / \mathrm{d}$ but produced fewer AEs and fewer discontinuations due to AEs. ${ }^{43}$

Diclofenac dispersible, a drinkable formulation of diclofenac, also has been shown to provide a rapid onset of pain relief in patients with acute soft tissue injuries. ${ }^{46} \mathrm{In}$ a randomized, blinded study of 48 adults with acute minor sports injuries and moderate to severe pain on movement, a single 50-mg dose of diclofenac dispersible was more effective than $500 \mathrm{mg}$ of naproxen granular in reducing pain intensity on movement and on pressure during the 4-hour period after dosing $(P \leq 0.04)$, and in producing rapid pain relief in the first hour $(P=0.034$ at 15 minutes $){ }^{47}$ Both agents were equally well tolerated.

Regardless of the formulation, the most common AEs associated with oral diclofenac have been gastrointestinal effects, including abdominal pain or cramping, constipation, indigestion, and nausea and, less frequently, abdominal distention, flatulence, vomiting, and upper and lower gastrointestinal complicated events including bleeding. ${ }^{16,18,39,48}$ The transient effect of oral antiarthritic doses on inhibition of platelet aggregation ${ }^{49}$ most likely accounts for the lower rates of ulcer complications associated with diclofenac use compared with other traditional NSAIDs. ${ }^{50-52}$ An analysis of data from clinical trials involving more than 85,000 patients, as well as postmarketing surveillance, found that oral diclofenac produces AEs in about $12 \%$ of patients and gastrointestinal AEs in $8 \%-10 \%$ of patients; approximately $1.5 \%-2 \%$ of patients discontinue treatment due to AEs. ${ }^{39}$ However, trials evaluating NSAID and COX-2 inhibitor used in patients with rheumatoid arthritis and osteoarthritis have reported discontinuation rates due to gastrointestinal AEs of 6-19 events per 100 patient-years. ${ }^{16,18,48}$ In a randomized controlled trial, the cumulative discontinuation rate due to gastrointestinal AEs in 3,518 patients receiving diclofenac sodium $50 \mathrm{mg}$ three times daily for osteoarthritis was 19.2 events per 100 patient-years. ${ }^{18}$

\section{Considerations for topical administration of diclofenac}

The stratum corneum - a heterogeneous structure containing protein (keratin), water, and lipids (cholesterol, phospholipids) - plays a crucial role in controlling the percutaneous absorption of drug molecules. ${ }^{53,54}$ Other key factors affecting absorption include drug-related factors (eg, lipophilicity, water solubility, molecular size, and vehicle), application conditions (open vs closed), and skin integrity, which is affected by disease, body site, and age. ${ }^{53}$

Hydration of the stratum corneum is an important determinant of drug absorption. Free diclofenac displays very low water solubility due to its high hydrophobicity and lipophilicity and, therefore, is paired with a salt to facilitate topical absorption. ${ }^{54,55}$ Several different salts of diclofenac are used in commercial products, including sodium, potassium, diethylamine, and N-(2-hydroxyethyl) pyrrolidine (also called epolamine) salts, and they have been considered for both oral and topical administration. ${ }^{56}$

Several formulations of diclofenac have also been developed, including gel, patch, and lotion formulations, which differ in their pharmacokinetics and systemic exposure. For example, a diclofenac aqueous gel formulation has been shown to produce $\mathrm{C}_{\max }$ levels more than double those seen with an emulsion gel..$^{57,58}$ The topical solution, a 1.5\% weight/weight diclofenac sodium topical solution, utilizes the permeation enhancer dimethyl sulfoxide (DMSO). Continuous application of the solution ( 80 drops 4 times daily for 7 days) is associated with a mean $T_{\max }$ of 4.0 hours and a mean $\mathrm{C}_{\max }$ of $19.4 \mathrm{ng} / \mathrm{mL}$, while continuous application of the diclofenac sodium 1\% gel (4 g 4 times daily for 7 days) is associated with a median $\mathrm{T}_{\max }$ of 14 hours and a mean $\mathrm{C}_{\max }$ of $15 \mathrm{ng} / \mathrm{mL} .{ }^{59,60}$ Additionally, continuous use of the topical solution resulted in approximately one-third of the systemic exposure seen after 1 month of applying a 3\% diclofenac sodium gel twice daily. ${ }^{59}$

Of the available diclofenac formulations, the epolamine salt of diclofenac offers specific advantages for topical administration. The surfactant property of diclofenac epolamine improves hydration of the stratum corneum, thereby lowering surface tension at the interface between the skin and the topical pharmaceutical preparation, which favors drug absorption through the skin. ${ }^{54}$ The use of epolamine as the ion-pairing agent enhances lipophilicity and water solubility compared with simple sodium or potassium salts of diclofenac and the permeation of diclofenac through the stratum corneum and epidermis. ${ }^{54-56,61,62}$ This was demonstrated by a direct comparison that showed the mean absorption rate (ka) of diclofenac epolamine into plasma was 1.4-fold greater than that of diclofenac sodium $(P<0.001){ }^{63}$ Interaction of the ion pair with cell membrane lecithins has also been demonstrated to enhance membrane permeability, further 
facilitating absorption of diclofenac through the external layer of the skin. ${ }^{54,64}$ This property omits the need for permeation enhancers, such as DMSO, which is used in other topical diclofenac formulations. ${ }^{65,66}$ When applied topically in a patch, diclofenac epolamine produces consistent and sustained drug release for 12 hours, with systemic drug exposure being 10-20 times lower over 48 hours than that following a single oral diclofenac dose. ${ }^{36} \mathrm{~A}$ recent report has indicated that, over 12 hours, plasma concentrations of diclofenac after twice-daily dosing for 4 consecutive days with the patch formulation of diclofenac epolamine were $<1 \%$ of those after a single 50-mg dose of oral diclofenac sodium enteric-coated tablets. ${ }^{37,67}$ The patch formulation of diclofenac epolamine has been shown to have a bioavailability of approximately $30 \%$ relative to a $1 \%$ gel formulation following continuous use over 7 days. The administration of diclofenac epolamine $1 \%$ gel led to a mean $\mathrm{T}_{\max }$ of 3.1 hours and mean $\mathrm{C}_{\max }$ of $28.1 \mathrm{ng} / \mathrm{mL}$, while the patch formulation led to a mean $\mathrm{T}_{\max }$ and $\mathrm{C}_{\max }$ of 5.4 hours and $17.4 \mathrm{ng} / \mathrm{mL}$, respectively. ${ }^{36}$

Pharmacokinetic studies have shown that topically applied diclofenac not only penetrates the stratum corneum and deeper skin layers, but also reaches joints, muscles, and synovial fluid in sufficiently high concentrations to exert, in principle, local therapeutic activity. ${ }^{68,69}$ In one study, the plasma bioavailability of a topical $4 \%$ spray gel of diclofenac sodium applied to a defined area on the thigh was 50 times lower than oral administration of diclofenac sodium tablets. However, bioavailability in subcutaneous adipose tissue and skeletal muscle tissue was 2-3 times higher with topical dosing than with oral dosing. ${ }^{70}$ In healthy volunteers, topical diclofenac was shown to improve the pain threshold of the quadriceps muscle, providing further evidence of deep penetration after topical application. ${ }^{71}$

\section{Efficacy and tolerability of topical diclofenac}

The efficacy and tolerability of various topical diclofenac formulations, including $1.5 \%$ diclofenac sodium solution, $1.16 \%$ diclofenac diethylamine gel, $140 \mathrm{mg}$ diclofenac hydroxyethylpyrrolidine patch, and $2 \%$ diclofenac lecithin organogel, in 19 clinical trials in more than 3,000 patients have been recently reviewed. ${ }^{72}$ Topical diclofenac agents have been shown to provide effective analgesia for both acute and chronic pain, including indications such as blunt impact injuries, soft tissue injuries, sprains, osteoarthritis, and epicondylitis. ${ }^{72}$ Efficacy of topical diclofenac was comparable with other topical NSAIDs (such as indomethacin gel, ketoprofen gel, piroxicam gel, and indomethacin patch) and some oral NSAIDs (diclofenac, naproxen, ibuprofen) in relieving acute and chronic pain. ${ }^{72}$

Topical diclofenac formulations are well tolerated; local skin irritation was the most frequent $\mathrm{AE}$ and was easily resolved. Incidence of systemic AEs has been shown to be similar to placebo, ${ }^{65}$ and the incidence of gastrointestinal AEs has been shown to be lower than oral diclofenac $(35 \%$ vs $48 \%, P=0.0006) .^{73}$ The use of DMSO to enhance percutaneous absorption of diclofenac sodium may contribute to the localized skin irritation, and in some patients, cause halitosis and body odor. ${ }^{65}$

Unlike conventional topical formulations (eg, gels), patches permit constant delivery of the active agent into the affected area by means of an occlusive bandage that promotes controlled and slow release of the drug. ${ }^{36,74}$ Occlusion has a favorable impact on drug absorption, sometimes improving penetration by $200 \%-300 \%$, which likely reflects changes in skin hydration and temperature. ${ }^{30}$

\section{Diclofenac epolamine topical patch}

The DETP 1.3\% (FLECTOR ${ }^{\circledR}$ Patch; King Pharmaceuticals ${ }^{\circledR}$ Inc, Bristol, TN), the first topical NSAID patch approved in the United States for the treatment of acute pain of minor strains, sprains, and contusions, is a topical delivery system composed of an adhesive material containing 1.3\% diclofenac epolamine, which is applied to a nonwoven polyester felt backing. ${ }^{75}$ The $10 \mathrm{~cm} \times 14 \mathrm{~cm}$ patch is covered by a polypropylene film release liner that is removed before the patch is applied to the skin. Each adhesive patch contains $180 \mathrm{mg}$ of diclofenac epolamine and inactive excipients, which enhance skin hydration and facilitate plaster adherence. Following application of DETP on the upper arm, peak plasma concentrations of $0.7-6.0 \mathrm{ng} / \mathrm{mL}$ were found at $10-20$ hours with plasma concentrations increasing to $1.3-8.8 \mathrm{ng} / \mathrm{mL}$ after twice-daily application of DETP for 5 days. ${ }^{75}$ Once absorbed, diclofenac is highly bound to serum albumin (>99\%), with a half-life of approximately 12 hours. ${ }^{75}$ Diclofenac undergoes metabolism and subsequent urinary and biliary excretion of the sulfate and glucuronide conjugates. ${ }^{75}$

DETP is indicated for the topical treatment of acute pain resulting from minor strains, sprains, and contusions. ${ }^{75}$ One patch is applied to the painful area and changed every 12 hours. $^{75}$

\section{Efficacy and tolerability of DETP in treating strains, sprains, and contusions}

The efficacy and tolerability of DETP in relieving acute pain due to minor sports injury were evaluated in a multicenter, 
randomized, placebo-controlled, parallel-group study of 222 adults who were injured within the 72 hours prior to study enrollment. ${ }^{76}$ The patch was applied directly over the injured site and changed twice daily for 2 weeks. Measures of pain intensity were evaluated on days 3,7 , and 14 . DETP was significantly more effective than placebo in relieving pain during daily activities as measured by a $100-\mathrm{mm}$ visual analog scale (VAS) and analyzed by the summed pain intensity difference during clinic visits on days $3(P=0.036)$ and $14(P=0.048) .{ }^{76}$ In addition, DETP was more effective than placebo based on daily diary recordings on days 3,7 , and 14 ( $P \leq 0.044)$. DETP was well tolerated; the incidence and intensity of AEs were comparable with those seen with the placebo patch. Rash was reported by $5 \%$ of patients in each treatment group, whereas pruritus was less common with DETP than placebo (5\% vs $17 \%){ }^{76}$

Comparable results were reported in a randomized, placebo-controlled, multicenter study conducted in the United States, which included 365 patients with minor sports injuries occurring within the previous 72 hours and pain $\geq 5$ on a numeric pain scale from 0 to $10 .{ }^{77} \mathrm{DETP}$ significantly reduced the median time to pain resolution (primary end point) compared with placebo (8.8 vs 12.4 days, $P=0.009$ ). In addition, DETP significantly reduced spontaneous pain compared with placebo, starting on day 6 and continuing until day 13 (all $P<0.05$ ). The tolerability of DETP was comparable with placebo, with no difference between treatments in the incidence or distribution of AEs. ${ }^{77}$

DETP was also assessed in a single-center, open-label study involving 101 patients with minor sports and overload injuries. ${ }^{78}$ DETP was applied topically twice daily for 14 days. Spontaneous pain - measured using a 4-point verbal scale ranging from 0 (no pain) to 3 (severe pain) - was reduced by $28 \%$ on day 7 and $60 \%$ on day $14 .{ }^{78}$ Comparable results were found for spontaneous pain, measured using a $10-\mathrm{cm}$ VAS, and pain on pressure, evaluated using the 4-point verbal scale. DETP was well tolerated, with all patients rating the tolerability of DETP to be good to excellent. ${ }^{78}$

Two 7-day, multicenter, randomized controlled studies evaluated DETP in the treatment of acute pain due to ankle sprains. In the first study, which enrolled 140 patients with benign ankle sprains, DETP significantly reduced spontaneous pain starting as early as 3 hours $(P=0.005)$ and continuing through day $3(P=0.004)$ and day $7(P=0.0008) .{ }^{79}$ DETP also reduced all secondary efficacy parameters (pain at rest and upon palpation, provoked passive pressure, and monopedal support) compared with placebo starting on day 3 and persisting through day 7. Similarly, DETP produced greater anti-inflammatory activity than placebo assessed by the decrease in edema as measured from the perimalleolar perimeter. Tolerability was judged to be good or very good by physicians in 69 of 70 patients in each group. ${ }^{79}$

In the second study, 134 patients with ankle sprains occurring within the previous 48 hours and having pain $\geq 50 \mathrm{~mm}$ on a $100-\mathrm{mm}$ VAS were randomly allocated to DETP or placebo group. ${ }^{80}$ DETP was superior to placebo in reducing pain on movement starting 4 hours after the first application $(P<0.02)$ and continuing up to the end of the 7-day study period ( $P<0.01$; Figure 2$)$. DETP was also superior to placebo in improving the secondary study end points, including pain during passive stretch, on pressure, and when standing

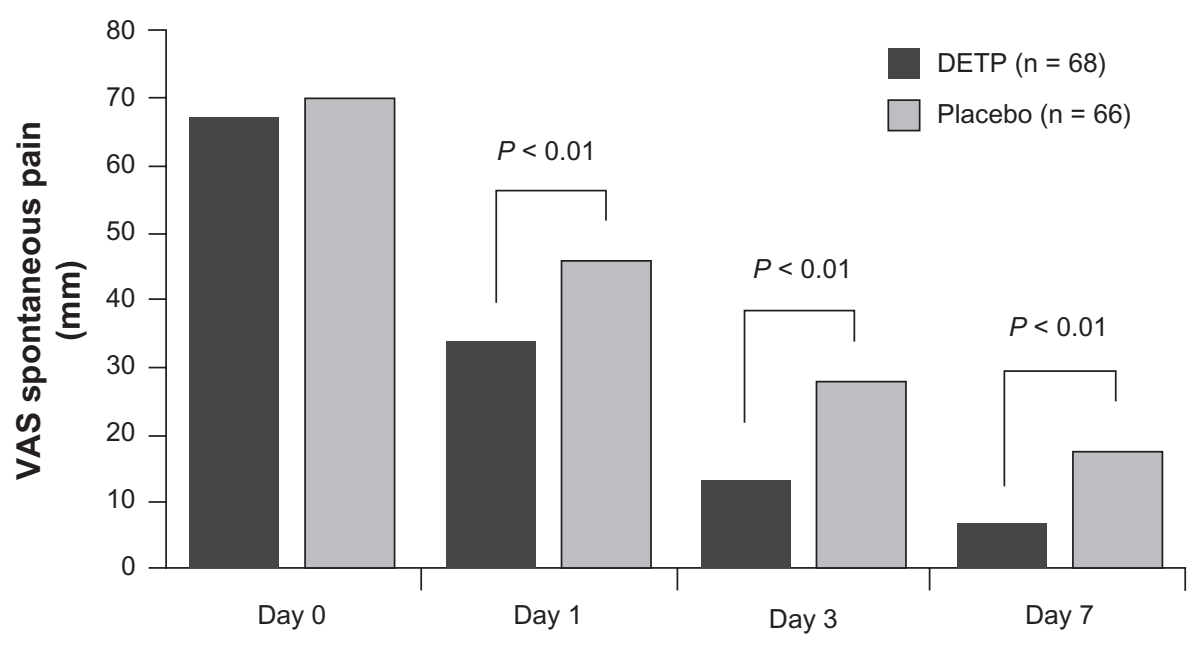

Figure 2 Comparison of diclofenac epolamine topical patch (DETP) and placebo in reducing pain on movement in patient with acute ankle sprains. Pain was measured on a 100-mm visual analog scale (VAS) at baseline (day 0) and on days I, 3, and 7 of twice-daily treatment. Copyright @ 2003, Elsevier Masson SAS Editeur, all rights reserved. Adapted with permission from Joussellin E. Flector Tissuge ${ }^{\circledR}$ in the treatment of painful ankle sprain. J Traumatol Sport. 2003;20:IS5-IS9. 
on one foot, by day $3(P=0.003, P=0.007, P=0.002$, respectively). ${ }^{80}$ No AEs were reported in this study.

\section{Efficacy and tolerability of DETP in other painful conditions}

DETP administered for 14 days to patients with epicondylitis significantly reduced the percentage of patients reporting moderate to intense pain compared with baseline and placebo $(P<0.05) .{ }^{81}$ At study completion, nearly a third fewer patients treated with DETP continued to experience intense pain compared with placebo. Pain on pressure was also significantly improved by DETP compared with placebo starting on day $7 .{ }^{81}$ DETP was well tolerated, with mild, temporary skin reactions seen in 1 patient in each study group.

DETP or placebo was applied topically every 12 hours for 2 weeks to 60 patients with periarticular tendinous disorders (eg, tendonitis, epicondylitis), rheumatologic disorders (eg, osteoarthritis, rheumatoid arthritis), or extra-articular pathologies (eg, fibrositis). ${ }^{74}$ In the subgroup with periarticular disorders, spontaneous pain, pain on pressure, and periarticular swelling improved progressively with DETP, with significant differences compared with placebo first seen on day $5(P \leq 0.05)$ and persisting to the end of the 14-day treatment period $(P \leq 0.01) \cdot{ }^{74}$ On day 7 , the efficacy of DETP was judged to be good or excellent by $70 \%$ of patients compared with only $7 \%$ in the placebo group. The efficacy of DETP was also superior to placebo in the subgroup with fibrositis starting on day $7 .{ }^{74}$ DETP applied twice daily was compared with $2 \mathrm{~g}$ of diclofenac diethylammonium emulgel 1.16\% applied 4 times per day for 14 days to patients with localized periarticular or tendinous disorders. ${ }^{82}$ Although both topical agents significantly improved spontaneous pain and pain on pressure, the effects of DETP were significantly greater than those of diclofenac diethylammonium $(P<0.001){ }^{82}$ Furthermore, the patient and physician assessments of treatment efficacy favored DETP (both $P<0.0001$ ). Both treatments were similarly well tolerated irrespective of the site or nature of the localized inflammation.

\section{Safety profile}

The most common AEs with DETP in placebo-controlled clinical trials were application site reactions $(11 \%)$, most commonly pruritus $(5 \%)$, occurring at rates comparable with placebo ( $12 \%$ and $8 \%$, respectively).${ }^{75}$ DETP should not be applied to nonintact or damaged skin including areas with, for example, dermatitis, eczema, lesions, burns, or wounds. $^{75}$
Gastrointestinal AEs were reported in $9 \%$ of patients treated with DETP compared with $6 \%$ of those who received placebo, ${ }^{75}$ representing a three fold to five fold improvement over the rates for traditional oral NSAIDs. ${ }^{50}$ Dyspepsia was reported in only $1 \%$ of patients treated with DETP. Regardless, DETP should be used with caution in patients with a history of ulcers or gastrointestinal bleeding. ${ }^{75}$

As with other NSAIDs, DETP has boxed warnings for cardiovascular and gastrointestinal risk and should be used with caution in patients with hypertension, congestive heart failure, and fluid retention; it is contraindicated in the treatment of perioperative pain following coronary artery bypass graft surgery. ${ }^{75}$ Treatment with DETP is not recommended in patients with advanced renal disease but, if initiated, close monitoring of renal function is advised. Patients who develop abnormal liver function tests, anemia, or abnormal platelet function during use should also be monitored and further evaluated.

The general precautions recommended for all NSAIDs also apply to DETP. DETP should not be taken by patients who have shown hypersensitivity to diclofenac or other NSAIDs, and since there are no well-controlled studies in pregnant women, the benefit and risk should be carefully weighed. ${ }^{75}$

The potential for drug-drug interactions should be considered when DETP is used by patients who are simultaneously using other drugs. ${ }^{75}$ This may be especially relevant in older patients who may have age-related physiological changes and comorbid conditions that require concomitant medications. ${ }^{83}$ In general, NSAIDs may reduce the antihypertensive effects of angiotensin-converting enzyme inhibitors and the natriuretic effects of furosemide and thiazide diuretics. NSAIDs can increase exposure to lithium and methotrexate, raising the possibility for greater toxicity by these agents, and augment the anticoagulant effects of warfarin, thereby raising risk of gastrointestinal bleeding. In addition, concomitant use of aspirin reduces binding of diclofenac to serum proteins, thereby increasing the possibility of AEs. ${ }^{75}$

A large proportion of the adult population in the United States is currently treated with low-dose aspirin for cardiovascular prophylaxis. In a recent Internet survey of 1,000 general practitioners in the United States, $85 \%$ of providers indicated that more than $25 \%$ of their patients were taking aspirin for preventive reasons. ${ }^{84}$ The concomitant use of low-dose aspirin and oral NSAIDs has been associated with an increased risk of serious gastrointestinal AEs. ${ }^{19}$ Although the use of gastroprotective agents, such as 
proton pump inhibitors, appears to lower the risk of serious gastrointestinal AEs, not all patients on NSAID therapy receive these agents. ${ }^{84}$ Therefore, patients currently being treated with low-dose aspirin and requiring concomitant NSAID therapy should be prescribed the lowest effective dose for the shortest time period. In this regard, topical NSAID formulations allow for the lowest systemic exposure, providing effective analgesic and anti-inflammatory clinical efficacy for the treatment of acute strains, sprains, and contusions. However, it is unlikely that controlled clinical studies will be performed to specifically examine the risk of NSAID-associated AEs in patients being treated for acute pain with topical NSAIDs and low-dose aspirin, as studies involving the treatment of acute pain usually include small sample sizes compared with those needed to adequately address this question.

\section{Conclusion}

Topical NSAIDs are effective in the treatment of acute pain due to soft tissue injuries. These agents are designed to work locally in the soft tissue and on peripheral nerves underlying the site of application and are not designed to be absorbed systemically in an appreciable amount. Controlled clinical trials have demonstrated that DETP is clinically effective in treating acute pain due to soft tissue injuries, producing clinical benefit within several hours of the first application and significant pain relief relative to placebo that is measurable within 3 days and maintained through the end of a 7-day to 14-day treatment period. Notably, DETP is well tolerated, with the incidence and intensity of AEs being comparable with placebo. On the basis of available evidence, DETP represents a generally safe and well-tolerated, clinically effective option for treating acute pain associated with strains, sprains, and contusions, along with other localized painful inflammatory conditions.

\section{Acknowledgments}

Writing and editorial assistance for this manuscript was provided by Jennifer Schwinn, RPh, of Quintiles Medical Communications, Parsippany, New Jersey, USA. Funding for writing and editorial support was provided by King Pharmaceuticals ${ }^{\circledR}$, Inc., Bridgewater, New Jersey, USA. Funders were involved in the review of the manuscript for accuracy of content.

\section{Disclosure}

Dr Lionberger is a consultant for Pfizer Inc, AesculpB Braun, Smith \& Nephew Pharmaceutical Ltd., and King Pharmaceuticals ${ }^{\circledR}$, Inc.
Dr Brennan has served as a consultant and on speaker's bureaus for Alpharma Pharmaceuticals, a wholly owned subsidiary of King Pharmaceuticals ${ }^{\circledR}$, Inc., Cephalon, Inc., Purdue Pharma, Forest Laboratories, Inc., PriCara, Eli Lilly, and Endo Pharmaceuticals.

\section{References}

1. Garrett WE Jr. Muscle strain injuries: clinical and basic aspects. Med Sci Sports Exerc. 1990;22(4):436-443.

2. Liu SH, Nguyen TM. Ankle sprains and other soft tissue injuries. Curr Opin Rheumatol. 1999;11(2):132-137.

3. Almekinders LC. Anti-inflammatory treatment of muscular injuries in sport. An update of recent studies. Sports Med. 1999;28(6):383-388.

4. Petrella R, Ekman EF, Schuller R, Fort JG. Efficacy of celecoxib, a COX-2-specific inhibitor, and naproxen in the management of acute ankle sprain: results of a double-blind, randomized controlled trial. Clin J Sport Med. 2004;14(4):225-231.

5. Arrington ED, Miller MD. Skeletal muscle injuries. Orthop Clin North Am. 1995;26(3):411-422.

6. Ivins D. Acute ankle sprain: an update. Am Fam Physician. 2006;74(10):1714-1720.

7. Gerber JP, Williams GN, Scoville CR, Arciero RA, Taylor DC. Persistent disability associated with ankle sprains: a prospective examination of an athletic population. Foot Ankle Int. 1998;19(10):653-660.

8. Rubin A, Sallis R. Evaluation and diagnosis of ankle injuries. Am Fam Physician. 1996;54(5):1609-1618.

9. van Rijn RM, van Os AG, Bernsen RM, Luijsterburg PA, Koes BW, Bierma-Zeinstra SM. What is the clinical course of ankle sprains? A systematic literature review. Am J Med. 2008;121(4):324-331.

10. Wolfe MW, Uhl TL, Mattacola CG, McCluskey LC. Management of ankle sprains. Am Fam Physician. 2001;63(1):93-104.

11. Ogilvie-Harris DJ, Gilbart M. Treatment modalities for soft tissue injuries of the ankle: a critical review. Clin J Sport Med. 1995;5(3):175-186.

12. Boutin RD, Fritz RC, Steinbach LS. Imaging of sports-related muscle injuries. Radiol Clin North Am. 2002;40(2):333-362, vii.

13. Mehallo CJ, Drezner JA, Bytomski JR. Practical management: nonsteroidal antiinflammatory drug (NSAID) use in athletic injuries. Clin J Sport Med. 2006;16(2):170-174.

14. Paulus HE, Bulpitt KJ. Nonsteroidal antiinflammatory agents and corticosteroids. In: Schumacher HR, Klippel JH, Koopman WJ, editors. Primer on the Rheumatic Diseases. 10th ed. Atlanta, GA: Arthritis Foundation; 1993:298-303.

15. Heyneman CA, Lawless-Liday C, Wall GC. Oral versus topical NSAIDs in rheumatic diseases. Drugs. 2000;60(3):555-574.

16. Laine L, Curtis SP, Kaur A, Cannon CP; for the MEDAL Steering Committee. Assessment of upper gastrointestinal safety of etoricoxib and diclofenac in patients with osteoarthritis and rheumatoid arthritis in the Multinational Etoricoxib and Diclofenac Arthritis Long-term (MEDAL) programme: a randomized comparison. Lancet. 2007;369(9560):465-473.

17. Lanas A, Serrano P, Bajador E, Fuentes J, Sainz R. Risk of upper gastrointestinal bleeding associated with non-aspirin cardiovascular drugs, analgesics and nonsteroidal anti-inflammatory drugs. Eur $J$ Gastroenterol Hepatol. 2003;15(2):173-178.

18. Baraf SB, Fuentealba C, Greenwald M, et al; for the EDGE Study Group. Gastrointestinal side effects of etoricoxib in patients with osteoarthritis: results of the Etoricoxib versus Diclofenac Sodium Gastrointestinal Tolerability and Effectiveness (EDGE) trial. J Rheumatol. 2007;34(2):408-420.

19. Sopena F, Lanas A. How to advise aspirin use in patients who need NSAIDs. Curr Pharm Des. 2007;13(22):2248-2260.

20. Brater DC. Effects of nonsteroidal anti-inflammatory drugs on renal function: focus on cyclooxygenase-2-selective inhibition. Am J Med. 1999;107(6A):S65-S70; discussion S70-S71. 
21. Cannon CP, Curtis SP, FitzGerald GA, et al; for the MEDAL Steering Committee. Cardiovascular outcomes with etoricoxib and diclofenac in patients with osteoarthritis and rheumatoid arthritis in the Multinational Etoricoxib and Diclofenac Arthritis Longterm (MEDAL) programme: a randomised comparison. Lancet. 2006;368(9549):1771-1781.

22. Rahme E, Joseph L, Kong SX, Watson DJ, LeLorier J. Cost of prescribed NSAID-related gastrointestinal adverse events in elderly patients. $\mathrm{Br} J$ Clin Pharmacol. 2001;52(2):185-192.

23. Hosie G, Bird H. The topical NSAID felbinac versus oral NSAIDs: a critical review. Eur J Rheumatol Inflamm. 1994;14(4):21-28.

24. Ballerini R, Casini A, Chinol M, Mannucci C, Giaccai L, Salvi M. Study on the absorption of ketoprofen topically administered in man: comparison between tissue and plasma levels. Int J Clin Pharmacol Res. 1986;6(1):69-72.

25. Stanos SP. Topical agents for the management of musculoskeletal pain. J Pain Symptom Manage. 2007;33(3):342-355.

26. Dreiser RL. Topical antirheumatic drug therapy: current practice and future trends. Eur J Rheumatol Inflamm. 1994;14(4):3-8.

27. Moore RA, Tramer MR, Carroll D, Wiffen PJ, McQuay HJ. Quantitative systematic review of topically applied non-steroidal anti-inflammatory drugs. BMJ. 1998;316(7128):333-338.

28. Brown MB, Martin GP, Jones SA, Akomeah FK. Dermal and transdermal drug delivery systems: current and future prospects. Drug Deliv. 2006;13(3):175-187.

29. Yang SI, Park HY, Lee SH, et al. Transdermal eperisone elicits more potent and longer-lasting muscle relaxation than oral eperisone. Pharmacology. 2004;71(3):150-156.

30. Varvel JR, Shafer SL, Hwang SS, et al. Absorption characteristics of transdermally administered fentanyl. Anesthesiology. 1989;70(6): 928-934.

31. Cleary GW. Transdermal delivery systems: a medical rationale. In: Shah VP, Mailbach HI, editors. Topical Drug Bioavailability, Bioequivalence, and Penetration. New York, NY: Plenum Press; 1993:17-68.

32. Payne R, Mathias SD, Pasta DJ, Wanke LA, Williams R, Mahmoud R. Quality of life and cancer pain: satisfaction and side effects with transdermal fentanyl versus oral morphine. J Clin Oncol. 1998;16(4):1588-1593.

33. Henzl MR, Loomba PK. Transdermal delivery of sex steroids for hormone replacement therapy and contraception. A review of principles and practice. J Reprod Med. 2003;48(7):525-540.

34. Sioufi A, Pommier F, Boschet F, Godbillon J, Lavoignat D, Salliere D. Percutaneous absorption of diclofenac in healthy volunteers after single and repeated topical application of diclofenac emulgel. Biopharm Drug Dispos. 1994;15(6):441-449.

35. Taburet AM, Singlas E, Glass RC, Thomas F, Leutenegger E. Pharmacokinetic comparison of oral and local action transcutaneous flurbiprofen in healthy volunteers. J Clin Pharm Ther. 1995;20(2):101-107.

36. Assandri A, Canali S, Giachetti C. Local tolerability and pharmacokinetic profile of a new transdermal delivery system, diclofenac hydroxyethylpyrrolidine plaster. Drugs Exp Clin Res. 1993;19(3):89-95.

37. Willis JV, Kendall MJ. Pharmacokinetic studies on diclofenac sodium in young and old volunteers. Scand J Rheumatol Suppl. 1978;(22): $36-41$.

38. Mason L, Moore RA, Edwards JE, Derry S, McQuay HJ. Topical NSAIDs for acute pain: a meta-analysis. BMC Fam Pract. 2004;5:10-19.

39. Small RE. Diclofenac sodium. Clin Pharm. 1989;8(8):545-558.

40. Catella-Lawson F, Reilly MP, Kapoor SC, et al. Cyclooxygenase inhibitors and the antiplatelet effects of aspirin. $N$ Engl J Med. 2001;345(25):1809-1817.

41. Gladding PA, Webster MW, Farrell HB, Zeng ISL, Park R, Ruijne N. The antiplatelet effect of six non-steroidal anti-inflammatory drugs and their pharmacodynamic interaction with aspirin in healthy volunteers. Am J Cardiol. 2008;101(7):1060-1063.

42. Machtey I. Diclofenac in the treatment of painful joints and traumatic tendinitis (including strains and sprains): a brief review. Semin Arthritis Rheum. 1985;15(2 Suppl 1):87-92.
43. Furberg B, Lerner A, Nyström B, Rosén M, Willig P. Antiphlogistics in acute inflammatory conditions in the soft tissues of the musculo-skeletal system - a double blind comparison of diclofenac and indomethecin. Curr Ther Res. 1985;38:523-527.

44. Duncan JJ, Farr JE. Comparison of diclofenac sodium and aspirin in the treatment of acute sports injuries. Am J Sports Med. 1988;16(6):656-659.

45. Meaders MA, Wiseman PL. A randomized multicenter comparison of piroxicam and diclofenac in the treatment of acute musculoskeletal injuries. Curr Ther Res. 1990;47:971-981.

46. Bakshi R, Rotman H, Shaw M, Sussman H. Double-blind, multicenter evaluation of the efficacy and tolerability of diclofenac dispersible in the treatment of acute soft-tissue injuries. Clin Ther. 1995;17(1): $30-37$.

47. Colombo G, Giombini A, Pamich T, et al. Diclofenac dispersible provides superior analgesia with faster onset of action compared to naproxen granular in patients with acute, painful, minor sports injuries. J Sports Med Phys Fitness. 1997;37(3):228-233.

48. Krueger K, Lino L, Dore R, et al. Gastrointestinal tolerability of etoricoxib in rheumatoid arthritis patients: results of the etoricoxib vs diclofenac sodium gastrointestinal tolerability and effectiveness trial (EDGE-II). Ann Rheum Dis. 2008;67(3):315-322.

49. Schwartz JI, Dallob AL, Larson PJ, et al. Comparative inhibitory activity of etoricoxib, celecoxib, and diclofenac on COX-2 versus COX-1 in healthy subjects. J Clin Pharmacol. 2008;48(6):745-754.

50. Goldstein JL, Lowry SC, Lanza FL, Schwartz HI, Doge WE. The impact of low-dose aspirin on endoscopic gastric and duodenal ulcer rates in users of a non-selective non-steroidal anti-inflammatory drug or a cyclo-oxygenase-2-selective inhibitor. Aliment Pharmacol Ther. 2006;23(10):1489-1498.

51. Goldstein JL, Eisen GM, Lewis B, Gralnek IM, Zlotnick S, Fort JG. Video capsule endoscopy to prospectively assess small bowel injury with celecoxib, naproxen plus omeprazole, and placebo. Clin Gastroenterol Hepatol. 2005;3(2):133-141.

52. Wilcox CM, Allison J, Benzuly K, et al. Consensus development conference on the use of nonsteroidal anti-inflammatory agents, including cyclooxygenase-2 enzyme inhibitors and aspirin. Clin Gastroenterol Hepatol. 2006;4(9):1082-1089.

53. Morgan CJ, Renwick AG, Friedmann PS. The role of stratum corneum and dermal microvascular perfusion in penetration and tissue levels of water-soluble drugs investigated by microdialysis. $\mathrm{Br} J$ Dermatol. 2003; 148(3):434-443.

54. Fini A, Fazio G, Rapaport I. Diclofenac/N-(2-hydroxyethyl)pyrrolidine: a new salt for an old drug. Drugs Exp Clin Res. 1993;19(3):81-88.

55. Fini A, Fazio G, Gonzalez-Rodriguez M, Cavallari C, Passerini N, Rodriguez L. Formation of ion-pairs in aqueous solutions of diclofenac salts. Int J Pharm. 1999;187(2):163-173.

56. Minghetti P, Cilurzo F, Casiraghi A, et al. Ex vivo study of transdermal permeation of four diclofenac salts from different vehicles. J Pharm Sci. 2007;96(4):814-823.

57. Haroutiunian S, Drennan DA, Lipman AG. Topical NSAID therapy for musculoskeletal pain. Pain Med. 2010;11(4):535-549.

58. Seth BL. Comparative pharmacokinetics and bioavailability study of percutaneous absorption of diclofenac from two topical formulations containing drug as a solution gel or as an emulsion gel. Arzneimittelforschung. 1992;42(2):120-122.

59. Pennsaid [package insert]. Varennes, Quebec: Nuvo Manufacturing; 2010 .

60. Voltaren Gel [package insert]. Parsippany, NJ: Novartis Consumer Health Inc; 2009

61. Ledwidge MT, Corrigan OI. Effects of surface active characteristics and solid state forms on $\mathrm{pH}$ solubility profiles of drug-salt systems. Int J Pharm. 1998;174:187-200.

62. O'Connor KM, Corrigan OI. Comparison of the physicochemical properties of the N-(2-hydroxyethyl) pyrrolidine, diethylamine and sodium salt forms of diclofenac. Int $J$ Pharm. 2001;222(2): 281-293. 
63. Maggi CA, Lualdi P, Mautone G. Comparative bioavailability of diclofenac hydroxyethylpyrrolidine vs diclofenac sodium in man. Eur J Clin Pharmacol. 1990;38(2):207-208.

64. Conte A, Ronca G, Petrini M, Mautone G. Effect of lecithin on epicutaneous absorption of diclofenac epolamine. Drugs Exp Clin Res. 2002;28(6):249-255.

65. Bookman AA, Williams KS, Shainhouse JZ. Effect of a topical diclofenac solution for relieving symptoms of primary osteoarthritis of the knee: a randomized controlled trial. CMAJ. 2004;171(14):333-338.

66. Rovati S, Garavani A. Research and development of a pharmaceutical technique allowing for improvement in clinical efficacy and simplicity of use of known drugs. Tribuna Medi Ticinese. 1996;61:204-207.

67. Rusca A, Mautone G, Sun S, Magelli M, Johnson F. Comparison of plasma pharmacokinetics of FLECTOR ${ }^{\circledR}$ Patch (diclofenac epolamine topical patch) and oral Voltaren ${ }^{\circledR}$ (diclofenac sodium enteric coated tablets) in healthy volunteers. J Pain. 2008;9(4 Suppl 1):45.

68. Davies NM, Anderson KE. Clinical pharmacokinetics of diclofenac. Therapeutic insights and pitfalls. Clin Pharmacokinet. 1997;33(3):184-213.

69. Radermacher J, Jentsch D, Scholl MA, Lustinetz, Frölich JC. Diclofenac concentrations in synovial fluid and plasma after cutaneous application in inflammatory and degenerative joint disease. Br J Clin Pharmacol. 1991;31(5):537-541.

70. Brunner M, Dehghanyar P, Seigfried B, Martin W, Menke G, Müller M. Favourable dermal penetration of diclofenac after administration to the skin using a novel spray gel formulation. Br J Clin Pharmacol. 2005;60:573-577.

71. Affaitati G, Vecchiet F, Lerza R, et al. Effects of topical diclofenac (DHEP plaster) on skin, subcutis and muscle pain thresholds in subjects without spontaneous pain. Drugs Exp Clin Res. 2001;27(2):69-76.

72. Zacher J, Altman RA, Bellamy N, et al. Topical diclofenac and its role in pain and inflammation: an evidence-based review. Curr Med Res Opin. 2008;24:925-950.

73. Tugwell PS, Wells GA, Shainhouse JZ. Equivalence study of a topical diclofenac solution $\left(\right.$ Pennsaid ${ }^{\circledR}$ ) compared with oral diclofenac in symptomatic treatment of osteoarthritis of the knee: a randomized controlled trial. J Rheumatol. 2004;31:2002-2012.
74. Galeazzi M, Marcolongo R. A placebo-controlled study of efficacy and tolerability of a nonsteroidal anti-inflammatory drug, DHEP plaster, in inflammatory peri-and extra-articular rheumatological diseases. Drugs Exp Clin Res. 1993;19(3):107-115.

75. Flector Patch [package insert]. Bristol, TN: King Pharmaceuticals ${ }^{\circledR}$, Inc.; 2009

76. Galer BS, Rowbotham M, Perander J, Devers A, Friedman E. Topical diclofenac patch relieves minor sports injury pain: results of a multicenter controlled clinical trial. J Pain Symptom Manage. 2000;19(4):287-294.

77. Rowbotham MC, Galer BS, Block JA, Backonja MM. Flector Tissugel ${ }^{\circledR}$ : efficacy and safety in the treatment of minor sports injuries. Data from a controlled trial in the United States. J Traumatol Sport. 2003;20:1S15-1S20.

78. Jenoure P, Segesser B, Luhti U, Gremion G. A trial with diclofenac HEP plaster as topical treatment in minor sport injuries. Drugs Exp Clin Res. 1993;19(3):125-131.

79. Saillant G, Auguste PH, Boyer C, et al. Study comparing the efficacy and tolerability of Flector Tissugel ${ }^{\circledR}$ to that of a placebo in the treatment of benign ankle sprain. Sports Med. 1998;72:1-5.

80. Joussellin E. Flector Tissuge $\mathrm{l}^{\circledR}$ in the treatment of painful ankle sprain. J Traumatol Sport. 2003;20:1S5-1S9.

81. Jenoure PJ, Rostan A, Gremion G, et al. Multicenter, double-blind, controlled clinical study of diclofenac Tissugel plaster in patients with epicondylitis. Medicina Dello Sport. 1997;50:285-292.

82. Rosenthal M, Bahous I. A controlled clinical study on the new topical dosage form of DHEP plasters in patients suffering from localized inflammatory diseases. Drugs Exp Clin Res. 1993;19(3):99-105.

83. Podichetty VK, Mazanac DJ, Biscup RS. Chronic non-malignant musculoskeletal pain in older adults: clinical issues and opioid intervention. Postgrad Med J. 2003;79(937):627-633.

84. Elnachef N, Scheiman JM, Fendrick AM, et al. Changing perceptions and practices regarding aspirin, nonsteroidal anti-inflammatory drugs, and cyclooxygenase-2 selective nonsteroidal anti-inflammatory drugs among US primary care providers. Aliment Pharmacol Ther. 2008;28(10):1249-1258.
Journal of Pain Research

\section{Publish your work in this journal}

The Journal of Pain Research is an international, peer-reviewed, open access, online journal that welcomes laboratory and clinical findings in the fields of pain research and the prevention and management of pain. Original research, reviews, symposium reports, hypothesis formation and commentaries are all considered for publication.

\section{Dovepress}

The manuscript management system is completely online and includes a very quick and fair peer-review system, which is all easy to use. Visit http://www.dovepress.com/testimonials.php to read real quotes from published authors. 